\title{
Téoros
}

Revue de recherche en tourisme

\section{Pour de nouvelles tables régionales}

\section{Audette Chaput}

Volume 25, numéro 1, printemps 2006

Entre la culture du goût et le goût de la culture

URI : https://id.erudit.org/iderudit/1071033ar

DOI : https://doi.org/10.7202/1071033ar

Aller au sommaire du numéro

\section{Éditeur(s)}

Université du Québec à Montréal

\section{ISSN}

0712-8657 (imprimé)

1923-2705 (numérique)

Découvrir la revue

Citer cet article

Chaput, A. (2006). Pour de nouvelles tables régionales. Téoros, 25(1), 42-42. https://doi.org/10.7202/1071033ar d'utilisation que vous pouvez consulter en ligne.

https://apropos.erudit.org/fr/usagers/politique-dutilisation/ 


\section{Pour de nouvelles tables régionales}

\section{Audette Chaput}

La cuisine et la gastronomie sont des éléments qui enrichissement l'expérience touristique culturelle. Si, en France, on a parlé au début du siècle dernier de Sainte Alliance entre le tourisme et la gastronomie pour bien marquer leur profonde synergie, aujourd'hui, dans de nombreux pays, fleurissent des initiatives nouvelles qui, dans le même esprit, mettent en valeur les produits régionaux. Ainsi on assiste à la mise sur pied de programmes de regroupement de l'offre comme l'Assiette de Pays en Normandie, Taste of Scotland, Taste of Nova Scotia, Taste the County, Prince Edward County (Ontario). Même en Australie, un mouvement s'est amorcé, il y a quelques années, sur l'initiative du chef québécois Serge Dansereau. Ce dernier est considéré comme le plus ardent promoteur des produits du terroir et sa cuisine met en valeur ce que la terre et la mer de son pays d'adoption peuvent offrir de mieux. Son engagement à redonner à la cuisine australienne un nouveau sens et sa passion pour les produits et la promotion du régionalisme lui ont permis de remporter un prix d'excellence. Le Québec ne pouvait être insensible à une tendance de fond qui désormais se manifeste partout sur la scène internationale.

\section{Initiative en développement:}

les "Tables Gourmandes au Québec »

Les dirigeants de la Fédération des Agricotours du Québec, gestionnaire des certifications Gites et Auberges du Passant ${ }^{\mathrm{MD}}$, Tables Champêtres ${ }^{\mathrm{MD}}$ et Relais du TerroirMD, ont constaté qu'il n'existe pas d'organisation dont les activités portent essentiellement sur la cuisine québécoise et les cuisines de nos régions, à l'exception d'un regroupement régional dans l'Est du Québec.

À leur avis, il est devenu primordial et pertinent de développer une "bannière » qui identifierait les Tables Gourmandes régionales, concept qui correspond aux attentes de certaines clientèles, locale, touristique et excursionniste. Le développement de cette bannière est en cours de réalisation. Elle sera implantée au cours de l'année 2006.
Le tourisme gourmand: une réalité actuelle...

On peut affirmer sans contredit que le tourisme culinaire, aussi appelé tourisme gourmand, a bel et bien pris son envol au Québec. De nos jours, le tourisme gourmand connaît un essor important et, parmi les éléments qui enrichissent l'expérience touristique, les plaisirs de la table prennent une place de choix. Au cours des dernières années, partout dans le monde, les produits alimentaires, les vins et la cuisine régionale ont suscité un intérêt croissant. Tout porte à croire que cette tendance devrait se maintenir. Les Québécois ne sont pas sans prendre part à ce mouvement international en faveur de l'utilisation des produits locaux, régionaux et du terroir, ainsi qu'au développement d'une cuisine québécoise exprimant les saveurs des régions.

\section{De nos racines culinaires} québécoises à l'expression des richesses alimentaires régionales...

"La cuisine au Québec » est l'expression d'un art culinaire de souche européenne qui s'est implanté dans un territoire nord-américain. C'est une cuisine basée sur une histoire, des particularités régionales, un savoir-faire et un goût caractéristiques à chaque région. Elle est l'expression créative des valeurs culturelles de tous ceux et celles qui ont contribué à bâtir le Québec et qui continuent de le faire.

\section{Les objectifs de la bannière sont:}

- Bonifier l'offre touristique québécoise en développant sa culture culinaire et en créant ainsi une offre en tourisme gourmand propre au réseau des Gîtes et Auberges du Passant ${ }^{\mathrm{MD}}$ certifiés de la Fédération des Agricotours du Québec, concept qui favorisera prioritairement la valorisation des spécificités patrimoniales, agroalimentaires, touristiques et culturelles.

- Doter le réseau d'une identité culinaire spécifique à la bannière et définir une image de marque bien distinctive et très caractéristique des régions du Québec.
Les assises de cette bannière reposent tout d'abord sur le développement des «typicités alimentaires » et des particularités culinaires de la région de l'établissement certifié et ensuite de l'ensemble des régions du Québec.

La bannière permet un regroupement axé sur la mise en valeur des produits agroalimentaires, sur la culture culinaire québécoise et les artisans de notre table de renommée internationale.

En plus de présenter à la clientèle locale et touristique une vitrine de nos produits et de notre cuisine, cette offre touristique est aussi un clin d'œil à notre patrimoine et à nos attraits culturels et touristiques.

La force de ce nouveau réseau repose essentiellement sur l'interaction entre les membres certifiés et les divers maillons des industries, alimentaire, culturelle et touristique.

L'offre de la bannière se reflète tant par les menus, les mets, la qualité de la cuisine, de l'accueil et du service en salle que par la complicité, l'implication, le professionnalisme et les connaissances de tout le personnel afin de mieux faire connaître notre cuisine et notre culture.

\section{Donner aux Tables Gourmandes une saveur qui les distinguera}

Les consommateurs auront la possibilité de déguster une cuisine authentique, fidèle à l'art culinaire d'apprêter les mets, représentative des habitudes alimentaires et des produits locaux, régionaux et québécois. Les Tables Gourmandes offriront à leur clientèle des menus ou des spécialités typiques qui expriment le meilleur des produits et des saveurs de leur région et du Québec.

Les Tables Gourmandes travailleront en complicité avec les producteurs, les pêcheurs et les transformateurs à améliorer leurs produits existants et à développer de nouveaux produits, répondant ainsi aux besoins des artisans de la table et aux attentes des clientèles.

Audette Chaput est directrice générale de la Fédération des Agricotours du Québec. 